\title{
Novel Flicker-Sensitive Visual Circuit Neurons Inhibited by Stationary Patterns
}

\author{
Roel de Haan, Yu-Jen Lee, and Karin Nordström \\ Department of Neuroscience, Uppsala University, 75124 Uppsala, Sweden
}

Many animals use visual motion cues for navigating within their surroundings. Both flies and vertebrates compute local motion by temporal correlation of neighboring photoreceptors, via so-called elementary motion detectors (EMDs). In the fly lobula plate and the vertebrate visual cortex the output from many EMDs is pooled in neurons sensitive to wide-field optic flow. Although the EMD has been the preferred model for more than 50 years, recent work has highlighted its limitations in describing some visual behaviors, such as responses to higher-order motion stimuli. Non-EMD motion processing may therefore serve an important function in vision. Here, we describe a novel neuron class in the fly lobula plate that clearly does not derive its input from classic EMDs. The centrifugal stationary inhibited flicker excited (cSIFE) neuron is strongly excited by flicker, up to very high temporal frequencies. The non-EMD driven flicker sensitivity leads to strong, nondirectional responses to high-speed, wide-field motion. Furthermore, cSIFE is strongly inhibited by stationary patterns, within a narrow wavelength band. cSIFE's outputs overlap with the inputs of well described optic flow-sensitive lobula plate tangential cells (LPTCs). Driving cSIFE affects the active dendrites of LPTCs, and cSIFE may therefore play a large role in motion vision.

\section{Introduction}

Many animals use visual motion cues to determine the relative motion of a target within their surroundings, to detect the rapid expansion of an object approaching imminent collision, or to maintain an intended trajectory. In both flies and vertebrates, motion is generally believed to be computed by local elementary motion detectors (EMDs) (Borst and Euler, 2011) by comparing the luminance change from one photoreceptor with the temporally delayed luminance change from its neighbor. Fly lobula plate tangential cells (LPTCs) (Borst and Egelhaaf, 1989) and motion-sensitive neurons in the vertebrate visual cortex (Price and Ibbotson, 2002) spatially pool output from many EMDs to generate sensitivity to wide-field optic flow. The fly retinal input is processed in the lamina and medulla before reaching the lobula complex, where some LPTCs synapse with descending neurons that control behavior (Strausfeld and Bassemir, 1985).

In flies, both LPTC physiology and quantitative behavior strongly support an underlying EMD-type input (Borst and Eu-

Received Dec. 14, 2012; revised April 7, 2013; accepted April 13, 2013.

Author contributions: R.d.H., Y.-J.L., and K.N. designed research; R.d.H. and Y.-J.L. performed research; K.N. contributed unpublished reagents/analytic tools; R.d.H., Y.-J.L., and K.N. analyzed data; R.d.H. and K.N. wrote the paper.

The authors declare no competing financial interests.

This work was funded by the Swedish Research Council (VR, 2008-2933, 2012-4740), the Swedish Royal Academy of Science (KVA, FOA10H-119), and AFRL (FA9550-11-1-0349). We thank A.B. Cederholms Lantbruk for access to cow dung with Eristalis larvae, and Jonas Henriksson, Tomas Måhlberg, and Linus Nilsson for software development and technical assistance. We thank the reviewers for excellent, constructive feedback, which greatly improved our paper.

This article is freely available online through the J Neurosci Author Open Choice option.

Correspondence should be addressed to Dr Karin Nordström, Department of Neuroscience, Uppsala University, Box 593, 75124 Uppsala, Sweden. E-mail: Karin.nordstrom@neuro.uu.se.

DOI:10.1523/JNEUROSCI.5713-12.2013

Copyright $\odot 2013$ the authors $\quad 0270-6474 / 13 / 338980-10 \$ 15.00 / 0$ ler, 2011). However, recent work has highlighted the limitations of the classic EMD in describing some visual behaviors, particularly responses to higher-order motion stimuli. These include reverse phi motion, in which the contrast polarity changes during motion, and theta motion where an object's internal pattern moves in the opposite direction to the object itself (Theobald et al., 2008; Tuthill et al., 2011; Lee and Nordström, 2012). NonEMD motion processing may therefore serve an important function in vision.

LPTC processing of $\mathrm{ON}$ and OFF stimuli, i.e., luminance increments and decrements, is separated via the lamina monopolar cells (LMCs) L1 and L2, respectively (Joesch et al., 2010). ON and OFF separation is also seen in other visual pathways. For example, small target motion detectors (STMDs) respond selectively to the motion of small targets (Nordström, 2012), by early visual separation of $\mathrm{ON}$ and OFF contrast changes (Wiederman et al., 2008). Local high-contrast changes thus play a major role in the input to motion processing. Several presynaptic (medulla and lamina) neurons are therefore also sensitive to flickering stimuli (Coombe et al., 1989; Jansonius and van Hateren, 1991; Wiederman et al., 2008). Flicker sensitivity has consequently largely been attributed to early visual processing. Here we challenge this view by describing a novel flicker-sensitive neuron class at a higherorder processing stage, in the fly lobula plate. The centrifugal stationary inhibited flicker excited (cSIFE) neuron is strongly excited by flicker, up to very high temporal frequencies. The nonEMD driven flicker sensitivity leads to strong, nondirectional responses to high-speed, wide-field motion.

Although cSIFE shares its flicker sensitivity with some neurons in the medulla and lamina (Coombe et al., 1989; Jansonius and van Hateren, 1991; Wiederman et al., 2008), it is also strongly inhibited by stationary patterns. This property has, to our knowl- 
edge, never been described before in flies. cSIFE is a heterolateral neuron with output arborizations covering the expanse of the lobula plate. Stimuli that drive cSIFE affects the response properties of a classic LPTC, suggesting that cSIFE may play a prominent role in motion processing.

\section{Materials and Methods}

Electrophysiology. Hoverflies (Eristalis spp.) were either wild-caught or bred from larvae collected from cow dung at Cederholms Lantbruk west of Uppsala, Sweden. At the time of experiments the hoverfly was immobilized with a mixture of bee's wax and resin. A hole was cut through the left backplate to gain access to the lobula plate.

Intracellular recordings were conducted at $21-24^{\circ} \mathrm{C}$ with sharp aluminosilicate electrodes (Harvard Apparatus) pulled on a P-1000 electrode puller (Sutter Instruments). Electrodes had a resistance of 40-220 M $\Omega$. The signal was amplified using a BA-03X amplifier (NPI Electronic), with $50 \mathrm{~Hz}$ electric noise filtered out with a HumBug (Quest Scientific). The signal was digitized at $10 \mathrm{kHz}$ using either a Powerlab $4 / 30$ with LabChart (AD Instruments), or a NiDAQ 16 bit data acquisition card (National Instruments, NI USB-6210) with the data acquisition toolbox in MATLAB (MathWorks).

Visual stimulation. During experiments the fly was immobilized in front of an RGB CRT monitor with a frame rate of $160 \mathrm{~Hz}$, a mean illuminance of $135 \mathrm{Lx}$, and a spatial resolution of $640 \times 480$ pixels. This corresponds to $\sim 100^{\circ} \times 75^{\circ}$ of the hoverfly's field of view, covering -10 to $65^{\circ}$ elevation and -60 to $40^{\circ}$ azimuth. Stimuli were generated with custom software (http://www.flyfly.se) using the psychophysics toolbox (http://psychtoolbox.org) in MATLAB.

The default stimulus consisted of a sinusoidal full-contrast, full-screen grating with a wavelength of $6^{\circ}$, presented either stationary or moving at $5 \mathrm{~Hz}$. A sinusoidal grating with $6^{\circ}$ wavelength and moving at $5 \mathrm{~Hz}$ is near-optimal for hoverfly LPTCs (Straw et al., 2006), and also excited cSIFE strongly. At $0 \mathrm{~Hz}$, this same wavelength inhibits cSIFE. We modified these variables to probe the response properties of cSIFE, as described in the text. All stimuli were shown for 1-2 s. Between trials the screen was left at mean luminance for a minimum of $2.8 \mathrm{~s}$.

For quantification of flicker sensitivity we used a full-screen, fullcontrast flicker stimulus. The flicker was either modulated sinusoidally (between 2 and $40 \mathrm{~Hz}$ ) or as a square-wave at $20 \mathrm{~Hz}$. The square-wave flicker was modulated between mean luminance and either black or white, switching every $1.5 \mathrm{~s}$.

For receptive field analysis, we used a full-screen, full-contrast, sinusoidal grating with $100^{\circ}$ wavelength, drifting at $5 \mathrm{~Hz}$. Because the screen had a width of $100^{\circ}$ it displayed only one full cycle of the grating at any point in time.

For interactions between cSIFE and LPTCs we recorded from male horizontal system north (HSN) neurons in the left lobula plate. We recorded HSN responses to a $30^{\circ}$ wide $\times 15^{\circ}$ high sinusoidal grating $\left(6^{\circ}\right.$ wavelength, $5 \mathrm{~Hz}, 10 \%$ contrast, preferred direction) with the border $30^{\circ}$ ipsilateral of the visual midline. We simultaneously stimulated cSIFE using a full screen-height sinusoidal grating in the right visual field, with the border placed $20^{\circ}$ contralateral of the visual midline. The $15^{\circ}$ wide grating had a wavelength of $6^{\circ}$ wavelength, was displayed at full contrast and remained stationary or drifted at $30 \mathrm{~Hz}$.

Data analysis. For a neuron to be defined as cSIFE it had to fulfill three properties: (1) Fire action potentials, (2) be inhibited by at least $50 \%$ by high-contrast stationary patterns, of any orientation, and (3) be excited by at least $50 \%$ by a grating drifting at $5 \mathrm{~Hz}$, in any direction. We recorded from 24 cSIFE neurons in 24 hoverflies.

Data were analyzed with custom written MATLAB scripts. For quantitative analysis we measured the mean spike rate during 0.2 to $1 \mathrm{~s}$ poststimulus onset, except for the analysis of the neurophysiological properties where three 200-ms-analysis windows are indicated in Figure $4 A, B$. The spontaneous rate was determined by averaging the spike rate for $0.5 \mathrm{~s}$ immediately preceding stimulus onset, except for the data in Figure 4 where we measured the mean spike rate between 0.7 and $0.2 \mathrm{~s}$ before stimulus onset.
All peristimulus time histograms (PSTHs) were generated after smoothing the individual traces with a $10 \mathrm{~ms}$ square-wave filter. To quantify the luminance dependence we plotted the PSTH as a function of the luminance change between two frames occurring $20 \mathrm{~ms}$ previously, to allow for neural delays (as estimated in Fig. 2). For frequency analysis we did a fast Fourier transformation (FFT) analysis of the PSTH data. We then quantified the power at 20 and at $40 \mathrm{~Hz}$.

Because cSIFE's strongest response is generated to the steepest luminance decrement (see Fig. 3C), we used the location of this part of the $100^{\circ}$ wavelength grating as a measure of the receptive field. The data were divided into $20 \mathrm{~ms}$ bins, each corresponding to $10^{\circ}$ of the visual field, assuming a $20 \mathrm{~ms}$ response delay (as estimated in Fig. 2). The stimulus drifted across the screen 5 or 10 times (i.e., for 1 or $2 \mathrm{~s}$ ). The first sweep was omitted from analysis.

Spike threshold analysis was performed in neurons in which the resting potential remained below $-45 \mathrm{mV}$ and the spikes had an amplitude of at least $40 \mathrm{mV}$. The spike threshold was defined as the membrane potential at the time point at which a spike was detected, i.e., immediately following spike initiation (for details, see Nordström et al., 2006). To determine the underlying membrane potential, each spike was removed from $0.5 \mathrm{~ms}$ before spike detection to $3.5 \mathrm{~ms}$ after detection, and the remaining $4 \mathrm{~ms}$ gap in the membrane potential was linearly interpolated between these two data points.

Repetitions $(n)$ were averaged within a neuron before averaging over animals $(N)$. Numbers in the text and figures show mean $(N) \pm$ SEM, unless otherwise indicated. We used paired $t$ tests to determine statistical significance $(p<0.05)$.

Anatomy. For morphological characterization we used iontophoretic injection with electrodes backfilled with 3\% Lucifer yellow [(LY) SigmaAldrich] dissolved in $0.1 \mathrm{M} \mathrm{LiCl}$. For the morphological reconstruction of the neuron in Figure $5 A$ we injected a current $(0.17-0.23 \mathrm{nA})$ for $21 \mathrm{~min}$, after physiological characterization. After filling the neuron, the brain was fixed in $4 \%$ paraformaldehyde for $10 \mathrm{~min}$ before being carefully dissected out of the head capsule. After removal of remaining tracheae, fatty tissue, and photoreceptors, the brain was dehydrated through an ethanol series of increasing concentration for $10 \mathrm{~min}$ each. The brain was cleared in methyl salicylate (Sigma-Aldrich) and mounted on a microscope slide with a concave well.

The neuron was visualized with a fluorescence microscope (Phase Contrast 2, Nikon) and a confocal microscope (Zeiss). The neuron was reconstructed by hand using the images from the confocal and fluorescence microscope (Nikon D700), and drawn using an Intuous5 touch medium drawing board (Wacom) with the aid of Adobe Photoshop (CS4).

\section{Results}

\section{Centrifugal stationary inhibited flicker excited}

We here describe a new lobula plate tangential neuron class, which we call centrifugal stationary inhibited flicker excited (CSIFE) based on the characteristic response properties (Fig. 1). cSIFE gives a spiking response (Fig. $1 A, B$ ). Its spontaneous rate varies between 0 and 35 spikes/s (Fig. 1C), normally distributed around a mean of $\sim 15$ spikes/s. cSIFE's spontaneous firing rate is strongly inhibited by stationary sinusoidal gratings $\left(6^{\circ}\right.$ wavelength, Fig. $1 A$ ), of any orientation (Fig. $1 D, N=15$ ). The same full-screen, full-contrast sinusoidal grating drifting at $5 \mathrm{~Hz}$ generates a strong excitation of the firing rate (Fig. $1 B$ ), with no directional preference (Fig. $1 E, N=18$ ). This differs substantially from classic LPTCs, which show a strong dependence on the direction of motion, as predicted by an EMD-type input (Borst et al., 2010).

When stimulated with a grating drifting at a constant temporal frequency, the response of classic LPTCs varies with stimulus wavelength (Borst et al., 2010), as expected of neurons getting their input from EMDs that spatially correlate luminance changes. In cSIFE, the peak inhibition to a stationary sinusoidal grating is located between $2^{\circ}$ and $10^{\circ}$, where the neuron is almost 
A

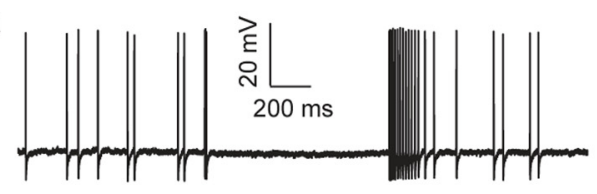

B
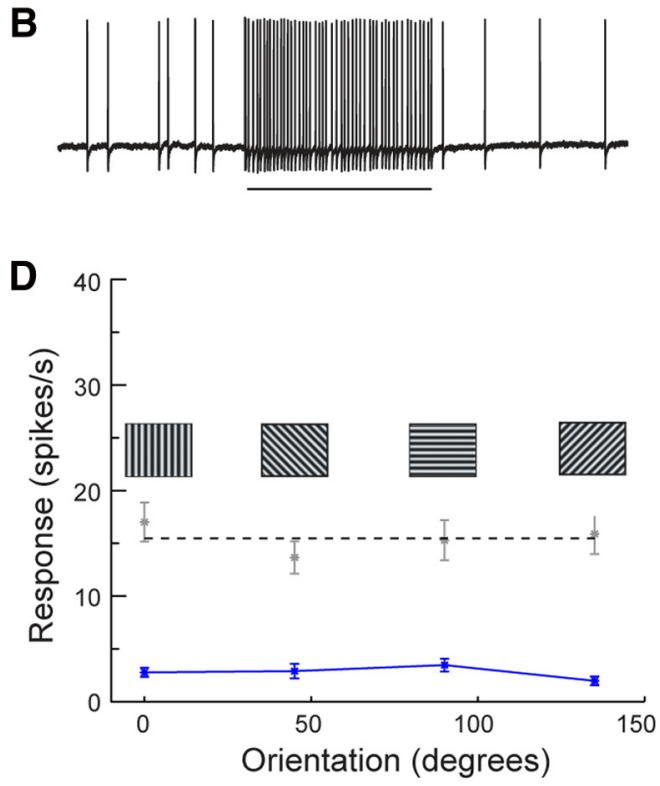

$\mathbf{F}$

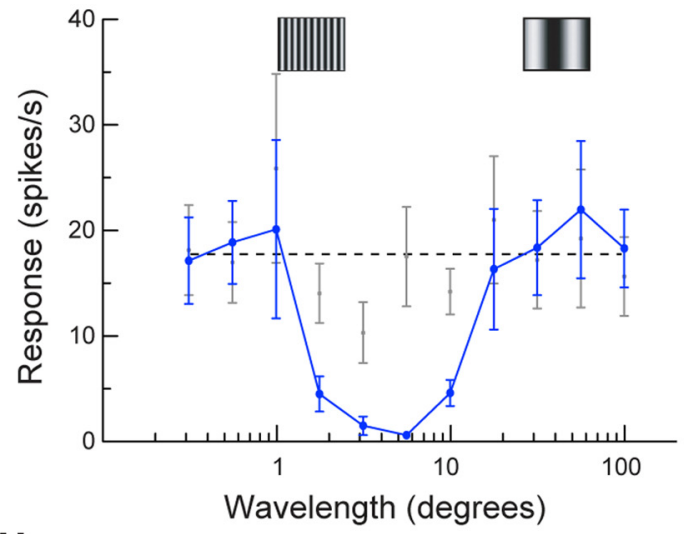

H

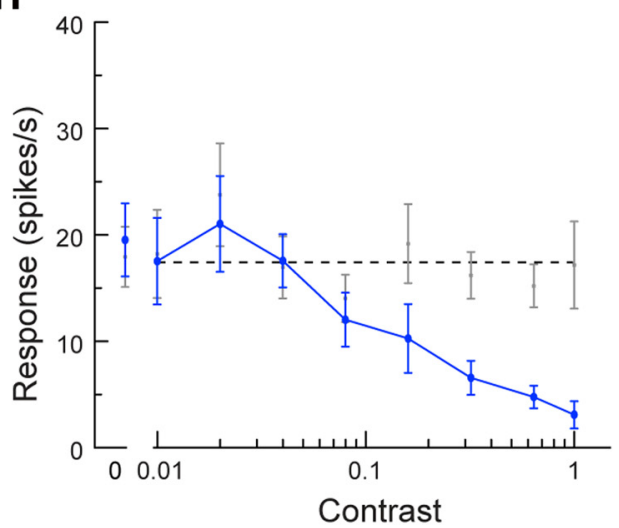

C

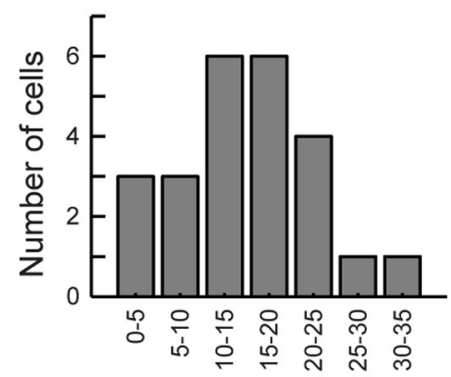

Spontaneous rate $(\mathrm{Hz})$

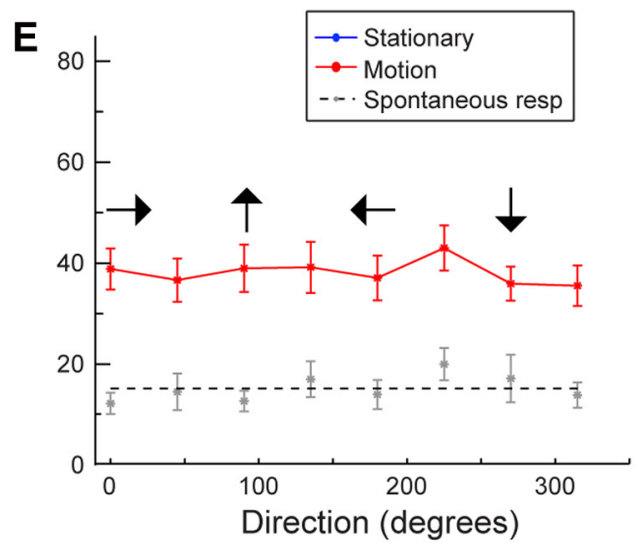

G
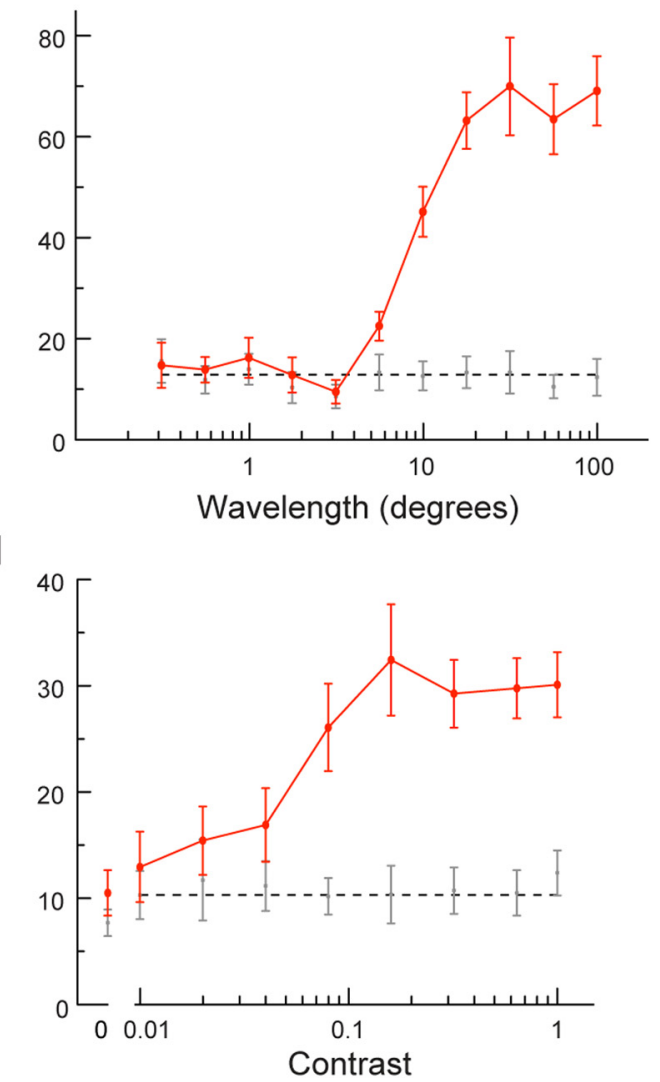

Figure 1. SIFE is inhibited by stationary patterns and excited by nondirectional motion. A, Neural response to a stationary sinusoidal grating $\left(6^{\circ}\right.$ wavelength) presented for $1 \mathrm{~s} . \boldsymbol{B}$, Neural response to a moving sinusoidal grating $\left(6^{\circ}\right.$ wavelength, $\left.5 \mathrm{~Hz}\right)$. The bar under the data trace indicates the stimulation time. $C$, The distribution of cSIFE spontaneous rates $(N=24)$. $D$, The response of cSIFE to a stationary grating as a function of pattern orientation $(N=18)$. Pictograms show the orientation of the pattern. $E$, The responses of CSIFE to a sinusoidal grating drifting in 8 directions $(N=15)$. Arrows indicate the direction the grating drifted. $F$, CSIFE's response as a function of a stationary sinusoidal grating's wavelength $(N=10)$. $G$, The response of $C$ SIFE as a function of pattern wavelength of a sinusoidal grating drifting at $5 \mathrm{~Hz}(N=$ 10). $\boldsymbol{H}$, The response of cSIFE as a function of contrast, to a stationary, full-screen sinusoidal grating $(N=10)$. $\boldsymbol{I}$, The response as a function of contrast, to a moving $(5 \mathrm{~Hz})$, sinusoidal grating $(N=10)$. 

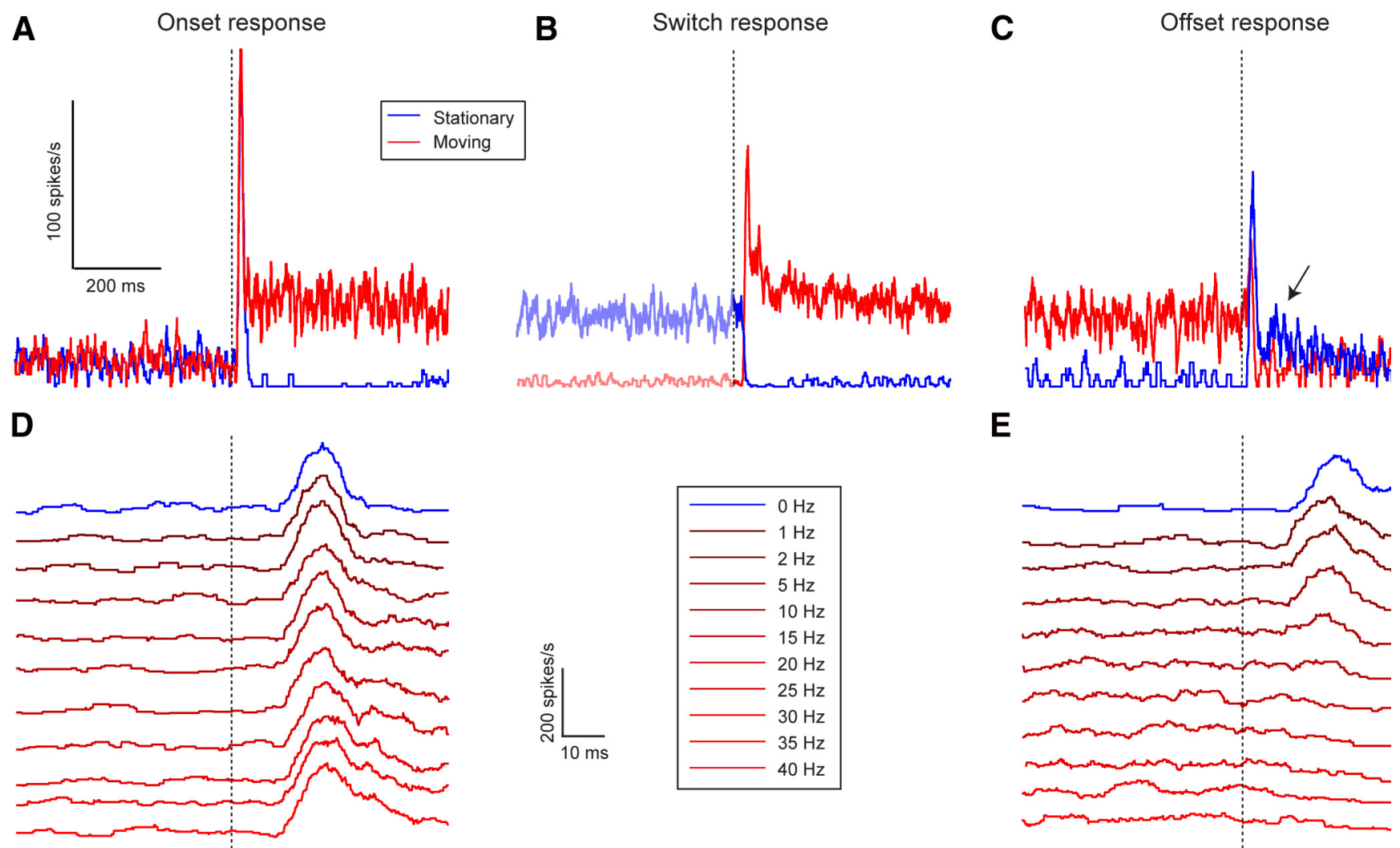

Figure 2. CSIFE gives strong transient responses to the onset of stimulation. $A$, The mean response of CSIFE to the onset of motion (red, $6^{\circ}$ wavelength, $10 \mathrm{~Hz}, N=7, A-C$ ) or of a stationary stimulus (blue, $6^{\circ}$ wavelength, $0 \mathrm{~Hz}$ ). The dashed vertical line indicates stimulus onset. $\boldsymbol{B}$, The mean response to a phase-aligned sinusoidal grating switching from motion $\left(6^{\circ}\right.$ wavelength, $10 \mathrm{~Hz}$ ) to stationary (blue), or vice versa (red). The dashed vertical line indicates the time of the switch. $C$, The response of cSIFE to the offset of motion (red, $6^{\circ}$ wavelength, $10 \mathrm{~Hz}$ ) or of a stationary stimulus (blue, $6^{\circ}$ wavelength, $0 \mathrm{~Hz}$ ). The dashed vertical line indicates stimulus offset. The scale bar is shared between $\boldsymbol{A}-\boldsymbol{C}$. $\boldsymbol{D}$, The onset transient for different temporal frequencies $(N=11)$. $\boldsymbol{E}$, The offset transient for different temporal frequencies $(N=11)$. The scale bar and legends are shared between $\boldsymbol{D}, \boldsymbol{E}$.

completely silenced (Fig. 1F, $N=10$ ). When the same stimulus is drifting across the screen at $5 \mathrm{~Hz}$ (Fig. $1 G, N=10$ ), the $6^{\circ}$ wavelength is close to the lower cutoff of wavelengths that drive the neuron (Fig. $1 G$, compare red and gray), whereas longer wavelengths strongly excite it, with no clear peak sensitivity.

cSIFE does not respond to low-contrast, stationary sinusoidal gratings (Fig. $1 H, N=10$ ). The spike rate decreases with contrast, and cSIFE is almost completely inhibited at full contrast (Fig. $1 H$ ). In response to moving stimuli (Fig. $1 I, N=10$ ), cSIFE's sigmoidal contrast dependence is similar to other motionsensitive neurons (Henrie and Shapley, 2005; de Haan et al., 2012).

Transient responses to high-contrast local luminance changes In our experiments the screen switches from mean luminance to displaying a high-contrast sinusoidal pattern at stimulus onset. Even if there is no net mean luminance difference from the meanluminance background, individual photoreceptors are exposed to high-contrast luminance changes. This stimulus onset generates a strong onset transient (peak after $22.4 \pm 1.1 \mathrm{~ms}$ ), before the spontaneous rate is either inhibited by a stationary pattern $(0 \mathrm{~Hz}$, Fig. $2 A$, blue $)$ or excited by a moving pattern $(10 \mathrm{~Hz}$, both $N=7$, Fig. $2 A$, red). The onset transient response does not depend on temporal frequency (Fig. $2 D, N=11$ ).

To dissect the motion response from the high-contrast onset transient, we display a grating that switches between being stationary and in motion (drifting at $10 \mathrm{~Hz}$ ) every $1.5 \mathrm{~s}$. With this stimulus individual photoreceptors are exposed to the same lu- minance at the onset of motion or inhibition. This reveals that the neural delays are similar for inhibition by a stationary pattern (Fig. $2 B$, blue, $N=7$ ) and for motion excitation (Fig. $2 B$, red, $N=$ 7). The inhibition is complete after $32.6 \pm 3.1 \mathrm{~ms}$, and the excitation peaks after $32.7 \pm 1.4 \mathrm{~ms}$ (Fig. $2 B$ ).

After inhibition by stationary patterns cSIFE displays an offset transient (Fig. $2 C$, blue, $N=7$ ), peaking after $27.3 \pm 1.8 \mathrm{~ms}$. This transient is followed by an increased spike rate, lasting for $\sim 200$ ms (Fig. 3C, arrow, blue data). The transient at the offset of image motion (Fig. $2 \mathrm{C}$, red, $10 \mathrm{~Hz}$ ) is smaller than at the onset of motion (Fig. $2 A$, red). Furthermore, the offset transient depends on the stimulus' temporal frequency (Fig. $2 E, N=11$ ). After low velocity motion $(1-5 \mathrm{~Hz})$ the transients are approximately equally strong, but they are faster (peak after $20.0 \pm 1.3 \mathrm{~ms}$ at $10 \mathrm{~Hz}$ ) and weaker than after inhibition (Fig. 2E, blue). The offset transient disappears completely after stimulation at higher temporal frequencies (Fig. 2E), which may be due to fatigue or adaptation-like processes, because these temporal frequencies drive the neuron strongly.

\section{cSIFE's excitatory response is flicker derived}

Stationary patterns inhibit cSIFE, whereas motion at 5 and $10 \mathrm{~Hz}$ excites it (Figs. 1,2). To investigate the response to motion further we drift the sinusoidal grating with a $6^{\circ}$ wavelength at different temporal frequencies. As seen before (Figs. 1, 2) cSIFE is inhibited by stationary patterns (Fig. $3 A$, blue data point, $N=11$ ). At low temporal frequencies $(1 \mathrm{~Hz})$ cSIFE fires at a spontaneous rate (Fig. $3 \mathrm{~A}$, 
A

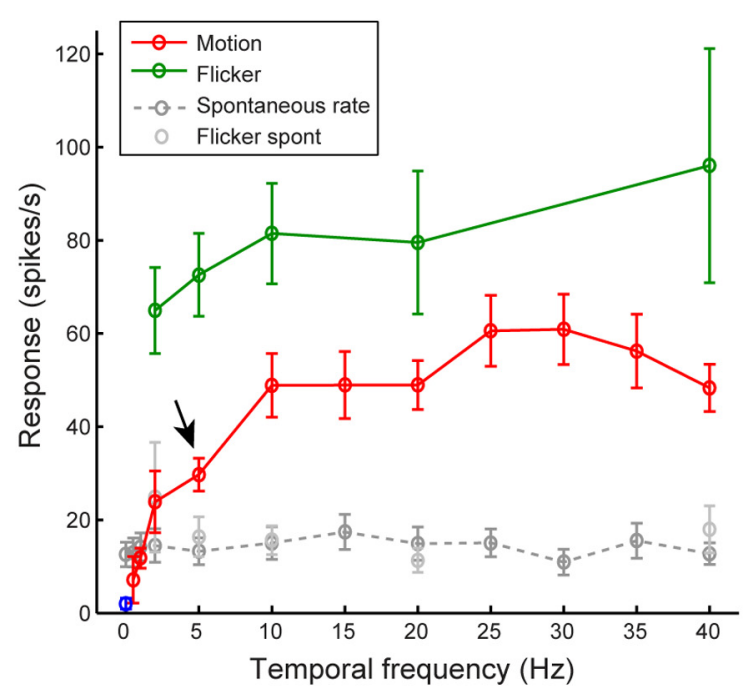

B

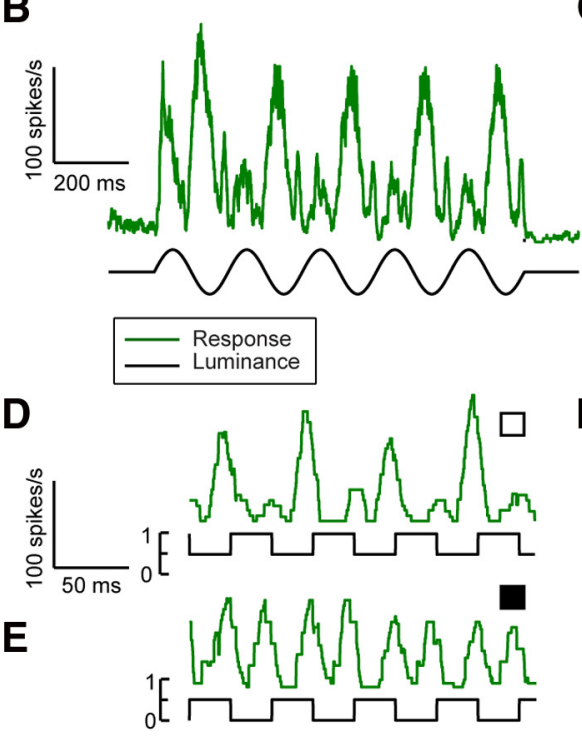

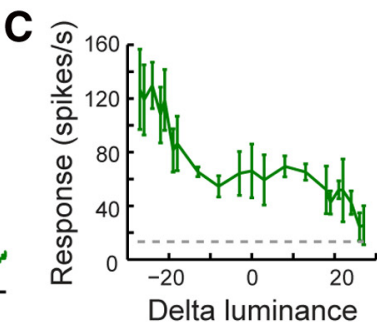

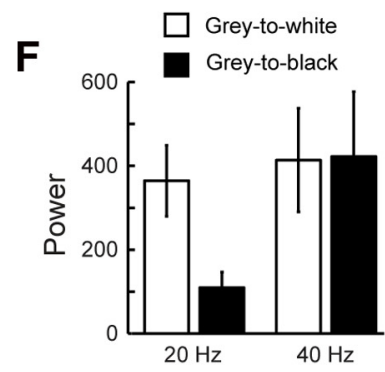

Figure 3. CSIFE is sensitive to high-frequency flicker. $\boldsymbol{A}$, The response of $\mathrm{CSIFE}$ as a function of temporal frequency of a full-screen, full-contrast sinusoidal grating $\left(6^{\circ}\right.$ wavelength, red, $N=11$, except at $0.5 \mathrm{~Hz}$ where $N=4$ ). The arrow indicates $5 \mathrm{~Hz}$, which was used in Figure 1 . The green data show the response to full-screen, sinusoidal flicker at a subset of these frequencies $(N=8$, except at 2 and $40 \mathrm{~Hz}$ where $N=6) . \boldsymbol{B}$, The mean response to full-screen, full-contrast sinusoidal flicker at $5 \mathrm{~Hz}(N=7)$. $\boldsymbol{C}$, The data from $\boldsymbol{B}$ plotted as a function of the luminance change between two frames, 20 ms previously $(N=7)$. $\boldsymbol{D}$, The mean response to full-screen, full-contrast square-wave flicker at $20 \mathrm{~Hz}$. The luminance flickered between mean luminance $(0.5)$ and white $(1 \mathrm{on}$ the scale bar, $\mathrm{N}=4$ ). $\boldsymbol{E}$, The mean response to a full-screen, full-contrast square-wave flicker at $20 \mathrm{~Hz}$. The luminance flickered between mean luminance $(0.5)$ and black $(0$ on the scale bar, $N=4)$. $\boldsymbol{F}$, The power after FFT of the data in $\boldsymbol{D}, \boldsymbol{E}$, quantified at 20 and $40 \mathrm{~Hz}$.

red), and it is progressively excited by higher frequencies, with a peak excitation around $25-30 \mathrm{~Hz}$.

At $40 \mathrm{~Hz}$, cSIFE still responds strongly, which is at much higher frequencies than many previously described dipteran LPTCs (Straw et al., 2006; Jung et al., 2011; Suver et al., 2012). Furthermore, since cSIFE's excitation does not have a clear wavelength peak (Fig. $1 G$ ), nor is there any direction-opponency (Fig. $1 E)$, this strongly argues against an underlying EMD-type input. To test this hypothesis we measure the response to luminance fluctuations that are not spatio-temporally correlated. When using full-screen, full-contrast, $5 \mathrm{~Hz}$ sinusoidal flicker cSIFE's response follows the stimulus' luminance modulation with response peaks every $200 \mathrm{~ms}$ (Fig. $3 B, N=7$ ). The response to flicker increases with temporal frequency (Fig. $3 A$, green, $N=$ $6-8$ ), and is stronger than the response to motion (Fig. $3 A$, red) at all frequencies tested.

To more directly investigate cSIFE's dependence on the luminance modulation we plot the response as a function of the luminance change $20 \mathrm{~ms}$ previously (to account for response delays, Fig. 2). This shows that cSIFE's response rate increases more when the stimulus gets darker (negative $x$ values, Fig. $3 C, N=7$ ), than when the luminance increases (positive $x$ values). To further investigate this apparent asymmetry in response to luminance increments and decrements, we display square wave flicker (20 $\mathrm{Hz}$ ), either modulated from gray to white or from gray to black. When the screen flickers between mean luminance and white, cSIFE responds strongly to decreasing luminance changes $(\sim 20$ ms to response peak, $N=4$, Fig. $3 D$ ), and only weakly to increasing luminance. This results in a $20 \mathrm{~Hz}$ response modulation (Fig. $3 D, N=4)$. However, when the screen flickers between mean luminance and black, cSIFE responds with almost equal strength to both phases of the stimulus (Fig. $3 E, N=4$ ). This results in a 40 $\mathrm{Hz}$ response modulation (Fig. $3 F, N=4$ ).

These data show that cSIFE receives excitatory, asymmetric $\mathrm{ON}$ and OFF flicker inputs, which are not spatio-temporally cor- related between photoreceptor inputs. At high luminance, responses to the stimulus' OFF phase are larger than to the $\mathrm{ON}$ phase.

\section{Paradoxical excitatory hyperpolarization and inhibitory depolarization}

After inhibition by a stationary pattern the spike rate is increased for $>100 \mathrm{~ms}$ (Fig. 2C, arrow, blue data), suggesting the presence of a slow inhibition-activated excitation. To investigate cSIFE's neurophysiological properties in more detail, we quantify the membrane potential, spike rate and spike threshold during stimulation with a sinusoidal grating that is either stationary or drifting at $5 \mathrm{~Hz}$ (Fig. 4, $N=5$ ).

Following an initial hyperpolarization, with its peak after 20 $\mathrm{ms}$, i.e., synchronized with the transient onset spikes described in Figure $2 A, D$, the membrane potential slowly rises to $0.8 \mathrm{mV}$ depolarized compared with rest (Fig. $4 A, C$, blue). This depolarization is peculiar, because cSIFE's spike rate is inhibited by stationary patterns (Fig. $4 A$, gray dots, $n=138$; Fig. $4 D$, blue, $N=$ $5)$. After stimulus offset, the membrane potential returns to prestimulus levels within a few hundred milliseconds (Fig. 4A), as do the spike threshold and firing rate (Fig. 4D,E).

At the onset of motion the membrane potential (Fig. $4 B$, red, $N=5$ ) is again transiently hyperpolarized (peak after $20 \mathrm{~ms}$ ), followed by a slower, sustained hyperpolarization (Fig. 4B, C, red). Paradoxically, however, cSIFE's firing rate increases (Fig. $4 B$, gray dots, $n=38$; Fig. $4 D$, red, $N=5$ ). Simultaneously, the spike threshold decreases (Fig. $4 E$ ), providing a mechanism for the increased firing rate (Fig. $4 D$ ) despite the membrane's hyperpolarization (Fig. 4C). After stimulus offset, complete recovery takes over a second for the membrane potential (Fig. $4 B, C$ ) and spike threshold (Fig. $4 B, E$ ), whereas the spike rate recovers faster (Fig. 4B,D).

Even if the membrane potential slowly adapts (Fig. 4A,B), there is no apparent spike rate adaptation after $2 \mathrm{~s}$ stimulation 
A

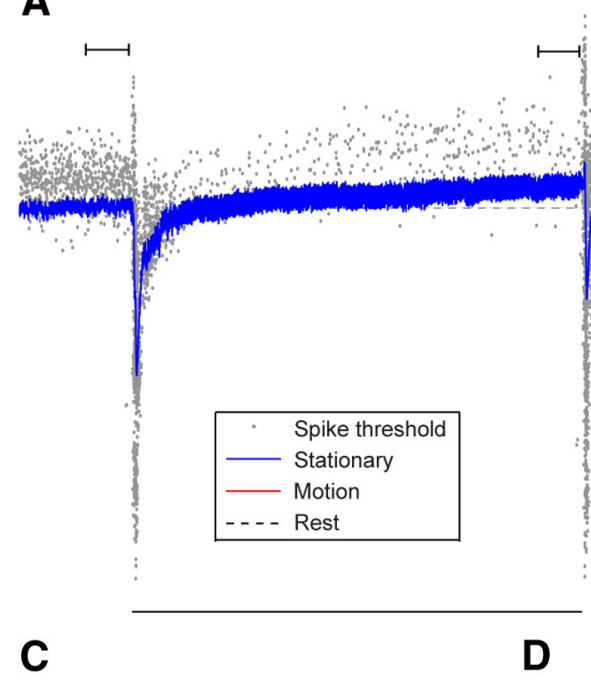

C

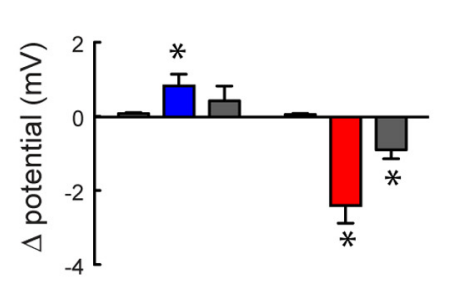

D

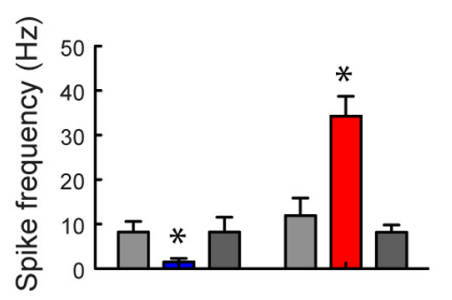

B
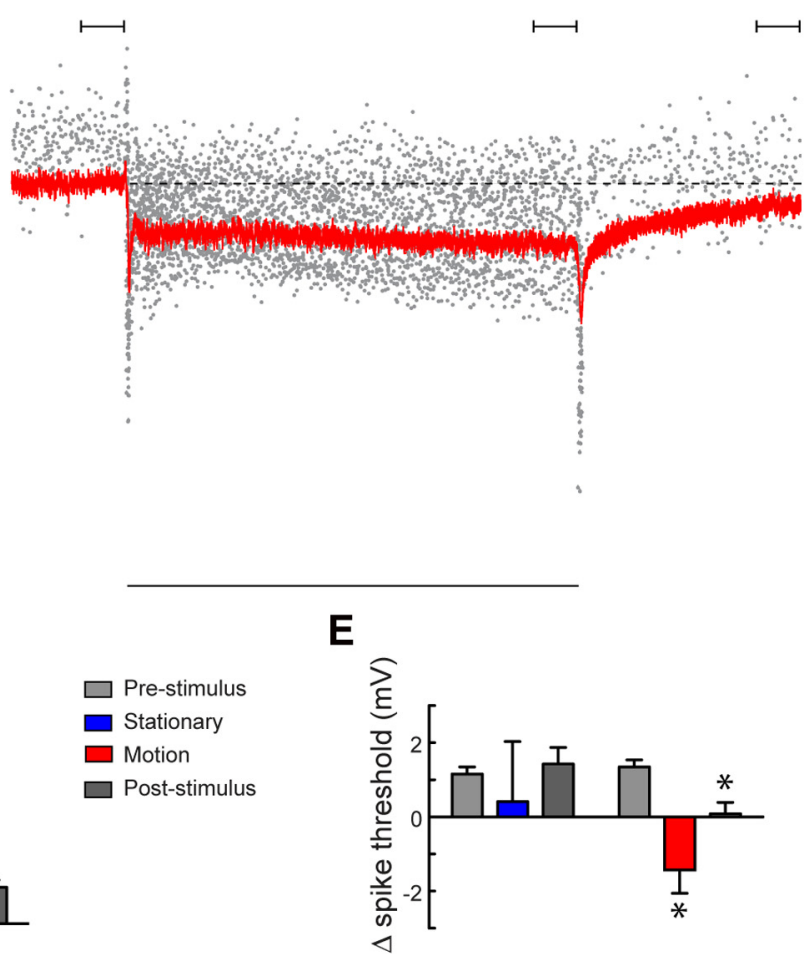

Figure 4. Paradoxical relationship between the membrane potential and the spike rate. $A$, The response of cSIFE to an inhibitory stimulus (full-contrast sinusoidal grating, $6^{\circ}$ wavelength, $0 \mathrm{~Hz}$ ). The blue line shows the mean membrane potential and the gray dots the spike threshold for every detected action potential $(N=5, n=138)$. $\boldsymbol{B}$, The response to a moving grating $\left(6^{\circ}\right.$ wavelength, $5 \mathrm{~Hz}$ ). The red line shows the mean membrane potential and the gray dots the spike threshold for each action potential $(N=5, n=38)$. The black bars above $A, B$ indicate the analysis windows used in $\boldsymbol{C}-\boldsymbol{E}$. The black bar below $\boldsymbol{A}, \boldsymbol{B}$ indicates the peristimulus duration. $\boldsymbol{C}$, The mean membrane potential difference measured for the last $200 \mathrm{~ms}$ before stimulus onset (gray), the last $200 \mathrm{~ms}$ of stimulation (blue and red), and $800-1000$ ms poststimulus offset (dark gray). The time points are indicated above the data in $A, B(N=5)$. $D$, The mean spike frequency before, during and after visual stimulation $(N=5)$. $\boldsymbol{E}$, The action potential threshold difference before, during, and after visual stimulation. ( $N=5$, except for the blue data where one neuron was completely quiet within the analysis window, and therefore no threshold could be determined, giving $N=4)$. Stars indicate significant difference $(p<0.05$, paired $t$ test $)$ compared with prestimulus levels.

A

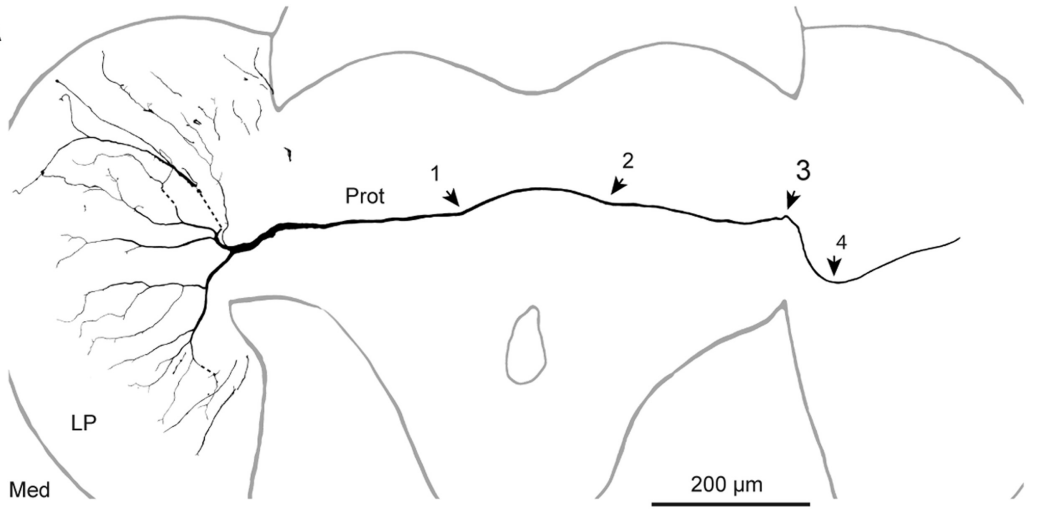

B

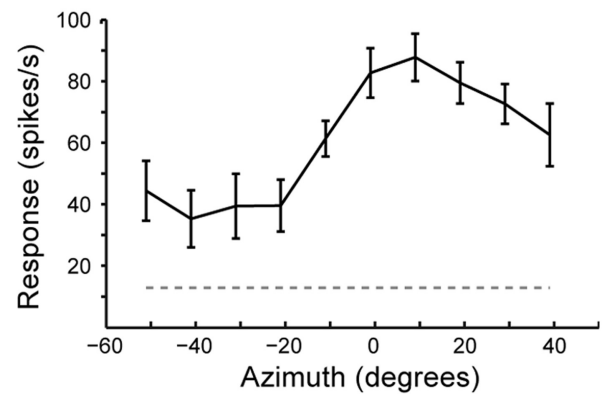

Figure 5. The morphology of CSIFE. A, Only the dendrites that were completely visible in the confocal or fluorescence images have been reconstructed, except for the three dashed lines, which indicate presumed branches. The neuron was recorded and filled in the left lobula plate. Arrowheads $1-4$ indicate two posterior dips of the main axon. Med, Medulla; LP, lobula plate; Prot, protocerebrum. $\boldsymbol{B}$, Receptive field of CSIFE. The position of the steepest luminance decrement of a sinusoidal grating $\left(100^{\circ}\right.$ wavelength, $\left.5 \mathrm{~Hz}\right)$ is plotted on the $x$-axis (see Materials and Methods, $N=9$ ).

(Fig. $4 B$, gray dots) or inhibition (Fig. $4 A$, gray dots). This observation is confirmed by the data in Figure 2, where the spike rate after $1.5 \mathrm{~s}$ stimulation with either a moving $(10 \mathrm{~Hz}$, Fig. $2 \mathrm{~B}, C$, red) or stationary grating (Fig. $2 B, C$, blue) is very similar to the spike rate during the first $0.5 \mathrm{~s}$ stimulation (Fig. $2 A, B$ ).

\section{Anatomy and receptive field}

To further characterize cSIFE we reconstruct the morphology of one neuron (Fig. 5A) after physiological investigation. This
cSIFE's receptive field is located in the right visual field (included in pooled data, $N=9$, Fig. $5 B$ ), suggesting that the left injection site is contralateral to its excitatory input. On the output side (Fig. $5 \mathrm{~A}$, left), the axon splits into two main branches at the medial border of the lobula plate, after making a posterior dip. One of these branches projects to the dorsal lobula plate and the other to the ventral part, with no overlap of their respective arborizations. The ventral and dorsal arborizations diverge and the finest branches cover the full dorsoventral extent of the lobula plate. 


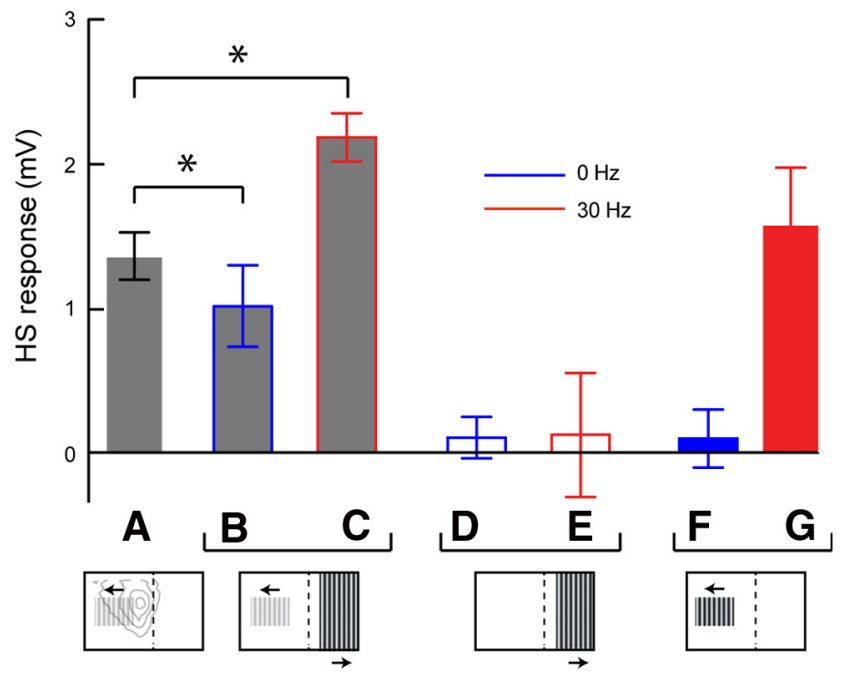

Figure 6. Stimuli that drive $\mathrm{SIFE}$ affect the response of $\mathrm{HS}$ neurons. $A$, The response of $\mathrm{HS}$ to a sinusoidal grating patch $\left(6^{\circ}\right.$ wavelength, $5 \mathrm{~Hz}, 10 \%$ contrast) in the ipsilateral visual field. In the figure below, the gray contours show the receptive field of male HSN (Nordström et al., 2008) and the dashed line the visual midline. $\boldsymbol{B}, \mathrm{HS}$ response to the same patch with simultaneous display of a stationary grating in the contralateral visual field ( $6^{\circ}$ wavelength, full contrast). C, HS response to the same patch with simultaneous display of a moving grating in the contralateral visual field ( $6^{\circ}$ wavelength, $30 \mathrm{~Hz}$ ). Asterisks indicate significant difference $(p<$ 0.05 , paired $t$ tests) compared with $\boldsymbol{A}$. $\boldsymbol{D}, \mathrm{HS}$ response to a stationary, full-contrast sinusoidal grating in the contralateral visual field. $\boldsymbol{E}$, HS response to a moving full-contrast sinusoidal grating in the contralateral visual field $(30 \mathrm{~Hz}) . \boldsymbol{F}, \mathrm{HS}$ response to an ipsilateral, stationary, sinusoidal grating $\left(6^{\circ}\right.$ wavelength, $0 \mathrm{~Hz}$, full-contrast). $\mathbf{G}, \mathrm{HS}$ response to an ipsilateral, moving, sinusoidal grating ( $6^{\circ}$ wavelength, $30 \mathrm{~Hz}$, full-contrast. $N=5$, except in $\boldsymbol{F}, \boldsymbol{G}$ where $\left.N=4\right)$.

The neuron's main axon traverses the central brain, making a characteristic posterior dip as it crosses the midline (Fig. 5A, between arrowheads 1 and 2). At the medial side of the contralateral (right) lobula complex, the axon makes two $\sim 90^{\circ}$ turns (Fig. $5 A$, arrowheads 3,4 ), in conjunction with a posterior dip. We were unable to reconstruct the fine dendrites in the right hemisphere.

cSIFE does not respond to small stimuli (data not shown), such as the $1 \times 3^{\circ}$ bars used to map LPTC receptive fields in our previous work (Nordström et al., 2008). However, in response to sinusoidal luminance changes cSIFE' spike rate increases most to the steepest luminance decrements (Fig. 3C). With a drifting grating with a $100^{\circ}$ wavelength, corresponding to the width of our display, at any point in time there will be one (and only one) complete cycle displayed. The location of the steepest luminance decrement of this grating then gives an approximation of cSIFE's receptive field. Of the $10 \mathrm{cSIFE}$ mapped this way, 9 have contralateral receptive fields (Fig. 5B), and one an ipsilateral receptive field (data not shown). cSIFE's highest sensitivity is located within $20^{\circ}$ of the visual midline (Fig. $5 B$ ).

\section{cSIFE affects HSN}

The morphological reconstruction shows axonal arborization throughout the lobula plate (Fig. $5 \mathrm{~A}$ ), suggesting that cSIFE could affect the response of LPTCs with inputs here, and that cSIFE may thereby play a role in the encoding of optic flow. To investigate this hypothesis we quantify the responses of HSN neurons in the left lobula plate to a nonsaturating, small sinusoidal grating $(10 \%$ contrast, $6^{\circ}$ wavelength, $5 \mathrm{~Hz}, 30^{\circ}$ wide by $15^{\circ}$ high, Fig. 6 A). Because the grating's border is placed $30^{\circ}$ to the left of the visual midline it will not stimulate cSIFE with outputs in the left lobula plate (Fig. 5A,B).
Stationary gratings inhibit cSIFE's spontaneous rate (Figs. 1-4). If there is a direct coupling between cSIFE and HSN we should see this inhibition affecting the HSN response. To inhibit cSIFE we add a full-contrast, stationary sinusoidal grating in its receptive field, $20^{\circ}$ to the right of the visual midline $\left(15^{\circ}\right.$ wide by $75^{\circ}$ high, $6^{\circ}$ wavelength, Fig. $6 B$ ), thus ensuring that the pattern does not stimulate the recorded HSN. Indeed, when cSIFE is inhibited, the HSN response decreases (Fig. 6 compare $A, B, N=$ $5, p<0.05)$.

In classic LPTCs, including HSN, a stationary grating generates no sustained response (Fig. 6F) (Maddess, 1986; Harris and O'Carroll, 2002). However, while a stationary grating inhibits cSIFE, it is excited by high-frequency motion (Fig. 3). If the HS response inhibition (Fig. 6B) is caused by cSIFE, we should see the opposite effect when the contralateral grating moves. Indeed, motion $\left(30 \mathrm{~Hz}, 6^{\circ}\right.$ wavelength), in cSIFE's receptive field increases the recorded HS response (Fig. $6 C, N=5, p<0.05$ ).

When we stimulate cSIFE's receptive field with the same stimuli $(0$ and $30 \mathrm{~Hz}$, full-contrast), without directly activating the recorded HS neuron, its membrane potential fluctuates around 0 $\mathrm{mV}$ (Fig. $6 D, E, N=5$ ). It thus appears as if stimulating cSIFE has an effect on active HSN dendrites. Hoverfly LPTCs respond to stimuli moving at $30 \mathrm{~Hz}$ (Fig. 6G) (Straw et al., 2006), so the observed HS response increase (Fig. $6 C$ ) could come from another LPTC than cSIFE. However, classic LPTCs do not respond to stationary stimuli (Fig. 6F) (Straw et al., 2006), indicating that the HS response decrease (Fig. $6 \mathrm{~B}$ ) is unlikely to come from another LPTC.

\section{cSIFE's input circuit}

Neither the excitatory nor the inhibitory response properties of cSIFE are compatible with the current main model for motion vision, the EMD. We therefore propose an alternative input model to cSIFE (Fig. 7A). In the proposed circuit early visual input is separated into ON and OFF luminance changes, which could be done via half-wave rectification in $\mathrm{L} 1$ and $\mathrm{L} 2$, respectively (Joesch et al., 2010). In our model circuit, the ON and OFF output is further separated into an inhibitory (Fig. 7A, blue) and an excitatory pathway (Fig. 7A, red).

The ON and OFF inputs are processed independently via temporal high-pass (HP) filters (Fig. 7A), leading to excitatory responses to high-frequency, high-contrast luminance changes. The OFF pathway provides stronger excitation than the ON pathway as suggested by the data in Figure $3 C$ (Fig. $7 A$, illustrated with wider red lines). Unlike the EMD (Hassenstein and Reichardt, 1956), there is no spatial correlation between neighboring inputs in the excitatory pathway (Fig. 7A). This leads to larger responses to full-screen flicker than to drifting gratings with the same temporal frequency (Fig. $3 A$ ) and to larger wavelengths (Fig. $1 H$ ), because these generate stronger luminance changes at the level of individual photoreceptors. Similarly, the lack of spatial correlation leads to insensitivity to the direction of motion (Fig. 1E).

For inhibition by stationary patterns the ON and OFF signals are first processed in temporal low-pass (LP) filters (Fig. 7A). The $\mathrm{ON}$ signal from one input is then subtracted from the OFF signal from a spatially separated input (Fig. 7A, "-"), and vice versa (not shown, for simplicity). The subtraction of inputs of opposite contrasts leads to inhibitory responses to stationary, highcontrast patterns (Figs. 1-4), but not to equiluminant stimuli. The subtraction is drawn here as occurring between nearest neighbors (Fig. 7A), but is likely to be generated over longer distances to give peak inhibition between wavelengths of $2-10^{\circ}$ (Fig. 1F). 
A

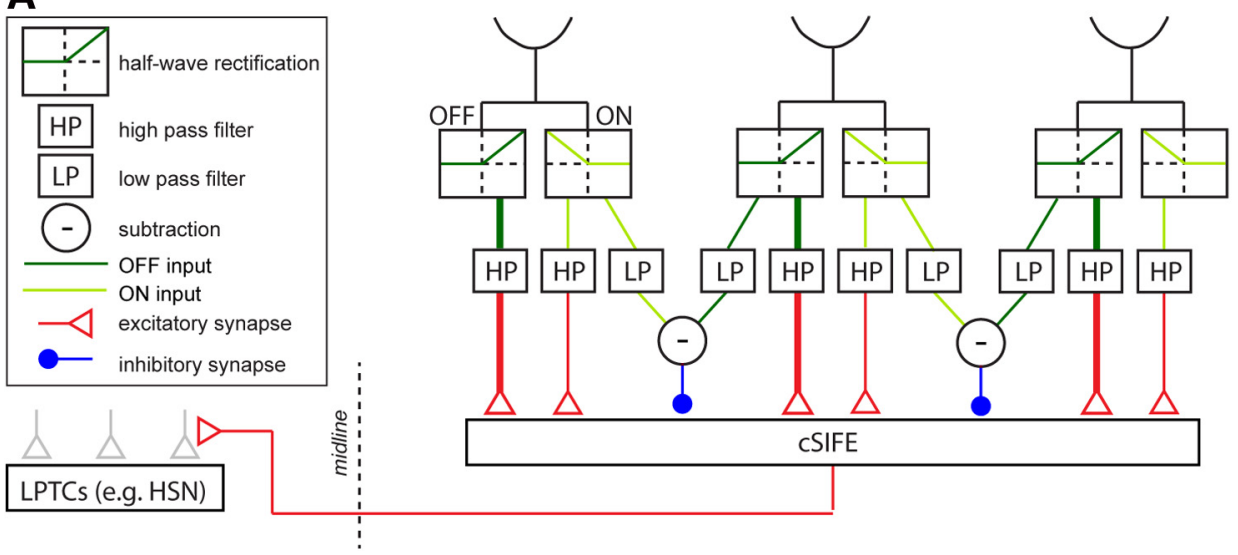

B

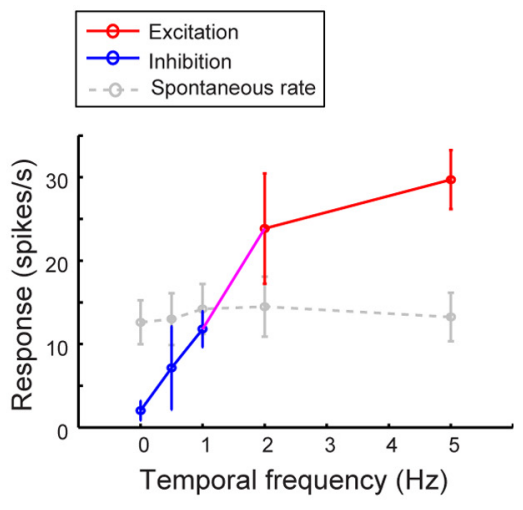

Figure 7. Proposed input circuitry to CSIFE. A, The diagram shows a proposed input circuitry to CSIFE. Early visual processing is separated into ON and OFF pathways, here shown as half-wave rectification. The $\mathrm{ON}$ and $\mathrm{OFF}$ inputs are then either subjected to temporal HP or LP filtering followed by subtraction of the opposite contrast from a neighboring unit (" - ", only one polarity shown here). The HP filtered output leads to excitatory responses in CIFE (red), whereas the subtracted output leads to inhibition (blue). The cSIFE axon crosses the visual midline where it may interact with other LPTCS, such as HSN. $\boldsymbol{B}$, The response of CSIFE to $0-5 \mathrm{~Hz}$ sinusoidal gratings ( $6^{\circ}$ wavelength). The data are replotted from Figure $3 \mathrm{~A}$.

The dynamics of the temporal LP and HP filters (Fig. 7A) lead to a separation of excitatory responses to fast luminance changes from inhibitory responses to those that are slow (or stationary). By magnifying the data from Figure $3 A$ we see that a sinusoidal grating moving at $0.5 \mathrm{~Hz}$ inhibits cSIFE's firing rate (Fig. $7 B, N=$ 4). This supports the presence of a temporal low-pass filter in the inhibitory pathway (LP, Fig. 7A). At $1 \mathrm{~Hz}$ cSIFE generates no response difference to spontaneous rate (Fig. $7 B, N=11$ ). This either means that the inward and outward currents between the excitatory and inhibitory systems balance each other out, or that neither system is activated by this stimulus.

\section{Discussion}

Here we describe the morphology and physiology of a new class of higher-order visual interneurons in the hoverfly lobula plate. In being inhibited by stationary patterns and excited by stimuli moving at high temporal frequencies, cSIFE's stimulus-response properties are different from other, previously described LPTCs (Hausen, 1982; Straw et al., 2006; Egelhaaf, 2008). cSIFE is a centrifugal spiking neuron and neither its excitatory nor its inhibitory inputs are consistent with EMD-type processing (Borst et al., 2010). The inhibitory and excitatory responses are derived from separate processing stages and ON and OFF contrast changes are coded asymmetrically. Furthermore, when the spike rate is inhibited by stationary patterns, the neuron is depolarized. When the neuron's spike rate is excited by moving patterns, its membrane potential is hyperpolarized. Finally, stimuli that drive cSIFE influence the response of HSN, and CSIFE may thus play a profound role in the coding of a wide range of visual stimuli.

\section{Neuroanatomy and place in the visual circuitry}

The morphological reconstruction of cSIFE (Fig. 5A) reveals a neuron with axons that colocalize with previously well described LPTCs (Hausen, 1984; Nordström et al., 2008). Because we were unable to morphologically reconstruct the input, we cannot determine from what visual neuropil it originates. The distance that the axon traverses is likely too long for the dye to diffuse in sufficient concentration, or may be the contralateral dendrites are too fine for the dye to penetrate completely. Nevertheless, because cSIFE's response properties are so different from other LPTCs, it unlikely receives input directly from these, but more likely from lobula or medulla interneurons.
Some of cSIFE's response properties are reminiscent of those of medullary transient cells (Osorio, 1991). Transient cells, including the tangential medulla amacrine cells (O'Carroll et al., 1992), are medulla neurons that give transient responses to the onset of static flicker (1-2 spikes), but no sustained response (Osorio, 1991). As a consequence, transient neurons give nondirectional responses to motion within their receptive field. However, although some of cSIFE's response properties could thereby be derived by excitatory input from transient cells, they cannot underlie the entire response repertoire. For example, transient neurons do not fire spontaneously (Osorio, 1991), and they are thereby not inhibited by stationary stimuli, like cSIFE (Figs. 1-4).

Medulla transient neurons may receive their input from onoff units (Arnett, 1972; Jansonius and van Hateren, 1991). Like cSIFE (Fig. 2A,D), on-off units respond strongly and transiently to high-contrast luminance changes. Furthermore, like cSIFE (Fig. $3 E$ ), on-off units show a frequency doubling in response to flicker (Jansonius and van Hateren, 1991). However, on-off units do not respond to stimuli $>20 \mathrm{~Hz}$, where cSIFE still generates near maximal responses (Fig. 3A). On-off units (Jansonius and van Hateren, 1991), rectified transient cells (Wiederman et al., 2008), and other transient neurons (Osorio, 1991) also adapt rapidly. We therefore find it unlikely that on-off units or other transient neurons provide all visual input to cSIFE.

\section{Flicker sensitivity and excitatory input}

The finding that cSIFE is strongly driven by flicker and motion cues at similar temporal frequencies suggest that the response to motion (Fig. 3A, red) is not an EMD-based response, but rather flickerinduced (Fig. $3 A$, green). Flicker stimulates individual photoreceptors at the same temporal frequencies as elementary motion (Fig. $3 A$, red), but will not generate directional motion cues, because it lacks the correct spatiotemporal correlation between neighboring photoreceptors (Franceschini et al., 1989).

Because cSIFE codes ON and OFF luminance changes asymmetrically (Fig. $3 C-F$ ) it is likely to receive ON and OFF inputs that were separated earlier in the visual pathway (Fig. 7A), similar to the processing suggested for the LPTCs (Joesch et al., 2010). Classic LPTCs also code ON (via L1) and OFF (via L2) luminance changes asymmetrically (Joesch et al., 2008, 2010), as do mudpuppy bipolar cells (Werblin and Dowling, 1969), rabbit (DeVries 
and Baylor, 1997), guinea pig (Ratliff et al., 2010), and primate (Chichilnisky and Kalmar, 2002) ganglion cells.

The fly lamina contains five monopolar cells, L1-L5 (Buschbeck and Strausfeld, 1996), which respond strongly to wide-field sinusoidally modulated flicker up to high temporal frequencies (Coombe et al., 1989). L4 is likely involved in the lateral inhibition between neighboring cartridges (Fischbach and Dittrich, 1989), but the role of L3 and L5 remains somewhat obscure. Maybe they provide input to the flickering pathway we describe. L3 is likely to synapse with TmY9 and Tm19 (Bausenwein et al., 1992). TmY neurons are particularly interesting because they have outputs in both the lobula and lobula plate (Fischbach and Dittrich, 1989). TmY9 has an extremely wide arborization in the medulla, which would allow modulation of responses across many optical columns. Furthermore, TmY9 has both cholinergic (Raghu et al., 2011) and GABA-ergic (Raghu et al., 2013) synapses, making it an interesting candidate neuron for the input circuitry to cSIFE.

\section{Sustained inhibition}

The inhibition by stationary patterns likely uses inhibition between neighboring inputs, because it is wavelength dependent (Fig. $1 F$ ) and does not occur when using equiluminant backgrounds. Inhibition is generated at wavelengths between 2 and $10^{\circ}$, with a peak at $3-5^{\circ}$ (Fig. $1 F$ ). We modeled this as a subtraction of the ON and OFF signals after LP filtering both (Fig. 7A). This ensures that there will only be an output from the subtraction stage when there is a contrast difference between two inputs (Fig. 1F,H).

In EMD-type processing, nearest neighbor interactions are likely supported by L4, which provides cholinergic inhibition between neighboring cartridges in the lamina and medulla (Takemura et al., 2011). In Eristalis the interommatidial angle in the frontal visual field is just $>1^{\circ}$ (Straw et al., 2006). A second stage of lateral inhibition, past the lamina, was previously suggested for STMDs (Nordström and O'Carroll, 2009). Despite the fact that STMDs are sharply tuned to moving targets, and do not respond to wide-field patterns, whether they are stationary or moving (Nordström et al., 2006), peak inhibition is seen at a distance of $\sim 3^{\circ}$ (Bolzon et al., 2009), suggesting potential shared inhibitory input.

Previous descriptions of sustained responses to stationary visual stimuli are rare, which makes sense because continuous signaling of a stationary stimulus carries redundancy, and indeed most often responses to continuous stimuli adapt away (de Ruyter van Steveninck et al., 1986; Borst and Egelhaaf, 1987; Kohn and Movshon, 2003; Solomon et al., 2004; Safran et al., 2007). In a few early recordings sustained excitatory responses to stationary, equiluminant stimuli were described, e.g., in the bullfrog optic nerve (Hartline, 1938) and cat striate cortex (Hubel and Wiesel, 1959). In a recent description of turtle retinal ganglion cells, there is an apparent, sustained inhibition by a stationary pattern (Greschner et al., 2002). However, the global luminance changed when the pattern appeared, making direct comparisons difficult.

\section{Converging pathways}

Because the excitation and inhibition have different wavelength optima (Fig. $1 F, G$ ) and opposite neurophysiological effects (Fig. 4), cSIFE is likely to receive separate excitatory and inhibitory inputs that converge in the neuron. In our proposed circuitry (Fig. 7A) the inhibitory pathway has an extra processing stage, but it is not impossible that the two pathways use a comparable number of presynaptic processing stages, because their time courses are similar (Fig. 2B).

Similar divergence of distinct information streams in early visual pathways (Werblin and Dowling, 1969; Burkhardt, 2011), followed by convergence at later stages, has been described in vertebrate retina. For example, divergent $\mathrm{ON}$ and OFF bipolar cell input converge on turtle ON-OFF ganglion cells (Greschner et al., 2002; Thiel et al., 2006). Furthermore, salamander ganglion cells have been shown to code for two or more features of the visual world, presumably due to mixed input from distinct bipolar cells (Fairhall et al., 2006). Parallel and subsequent convergent visual processing, as in cSIFE, may provide a universal template, to facilitate maximal information transmission with minimal redundancy (Koch et al., 2006; Butts et al., 2007; Field and Chichilnisky, 2007; Priebe and Ferster, 2012).

\section{Behavioral function}

The broad output coverage of cSIFE over a wide extent of the lobula plate (Fig. $5 \mathrm{~A}$ ) indicates a universal integration of the transmitted information by classical LPTCs. Indeed, our data show a possible influence of cSIFE on the responses of one LPTC, the HSN neuron (Fig. 6). Whereas the visual inputs in the lamina and medulla are highly conserved across taxa (Buschbeck and Strausfeld, 1996), neurons in the lobula plate show speciesspecific variation (Buschbeck and Strausfeld, 1997). It is therefore possible that cSIFE serves a species-specific role in hoverflies. Hoverflies are characterized by their ability to hover stationary for prolonged periods of time, followed by extreme high-speed pursuits of conspecifics (Fitzpatrick and Wellington, 1982). Neurons such as cSIFE would serve a useful role during this behavior, where a static or near-static surrounding, and consequently an inhibited neuron, would indicate successful hovering. Contrasting, high-speed motion in any direction, as generated during pursuit, would strongly stimulate the neuron. The discovery of cSIFE would thus enable coding both these behaviors by one neuron.

\section{References}

Arnett DW (1972) Spatial and temporal integration properties of units in first optic ganglion of dipterans. J Neurophysiol 35:429-444. Medline

Bausenwein B, Dittrich AP, Fischbach KF (1992) The optic lobe of Drosophila melanogaster: II. Sorting of retinotopic pathways in the medulla. Cell Tissue Res 267:17-28. Medline

Bolzon DM, Nordström K, O'Carroll DC (2009) Local and large-range inhibition in feature detection. J Neurosci 29:14143-14150. CrossRef Medline

Borst A, Egelhaaf M (1987) Temporal modulation of luminance adapts time constant of fly movement detectors. Biol Cybern 56:209-215. CrossRef

Borst A, Egelhaaf M (1989) Principles of visual motion detection. Trends Neurosci 12:297-306. Medline

Borst A, Euler T (2011) Seeing things in motion: models, circuits, and mechanisms. Neuron 71:974-994. CrossRef Medline

Borst A, Haag J, Reiff DF (2010) Fly motion vision. Annu Rev Neurosci 33:49-70. CrossRef Medline

Burkhardt DA (2011) Contrast processing by ON and OFF bipolar cells. Vis Neurosci 28(1):69-75. CrossRef Medline

Buschbeck EK, Strausfeld NJ (1996) Visual motion-detection circuits in flies: small-field retinotopic elements responding to motion are evolutionarily conserved across taxa. J Neurosci 16:4563-4578. Medline

Buschbeck EK, Strausfeld NJ (1997) The relevance of neural architecture to visual performance: phylogenetic conservation and variation in dipteran visual systems. J Comp Neurol 383:282-304. Medline

Butts DA, Weng C, Jin J, Yeh CI, Lesica NA, Alonso JM, Stanley GB (2007) Temporal precision in the neural code and the timescales of natural vision. Nature 449:92-95. CrossRef Medline

Chichilnisky EJ, Kalmar RS (2002) Functional asymmetries in ON and OFF ganglion cells of primate retina. J Neurosci 22:2737-2747. Medline 
Coombe PE, Srinivasan MV, Guy RG (1989) Are the large monopolar cells of the insect lamina in the optomotor pathway? J Comp Physiol A Neuroethol Sens Neural Behav Physiol 166:23-35.

de Ruyter van Steveninck RR, Zaagman WH, Mastebroek HAK (1986) Adaptation of transient responses of a movement-sensitive neuron in the visual system of the blowfly Calliphora erythrocephala. Biol Cybern 54: 223-236. CrossRef

de Haan R, Lee YJ, Nordström K (2012) Octopaminergic modulation of contrast sensitivity. Front Integr Neurosci 6:55. CrossRef Medline

Devries SH, Baylor DA (1997) Mosaic arrangement of ganglion cell receptive fields in rabbit retina. J Neurophysiol 78:2048-2060. Medline

Egelhaaf M (2008) Fly vision: neural mechanisms of motion computation. Curr Biol 18:R339-R341. CrossRef Medline

Fairhall AL, Burlingame CA, Narasimhan R, Harris RA, Puchalla JL, Berry MJ 2nd (2006) Selectivity for multiple stimulus features in retinal ganglion cells. J Neurophysiol 96:2724-2738. CrossRef Medline

Field GD, Chichilnisky EJ (2007) Information processing in the primate retina: circuitry and coding. Annu Rev Neurosci 30:1-30. CrossRef Medline

Fischbach K, Dittrich A (1989) The optic lobe of Drosophila melanogaster: I. A Golgi analysis of wild-type structure. Cell Tissue Res 258:441-475.

Fitzpatrick S, Wellington W (1982) Insect territoriality. Can J Zool 61:471-486.

Franceschini N, Riehle A, Le Nestour A (1989) Directionally selective motion detection by insect neurons. In: Facets of vision (Stavenga DG, Hardie RC, eds), pp 360-390. Berlin Heidelberg: Springer.

Greschner M, Bongard M, Rujan P, Ammermüller J (2002) Retinal ganglion cell synchronization by fixational eye movements improves feature estimation. Nat Neurosci 5:341-347. Medline

Harris RA, O'Carroll DC (2002) Afterimages in fly motion vision. Vision Res 42:1701-1714. CrossRef Medline

Hartline HK (1938) The response of single optic nerve fibers of the vertebrate eye to illumination of the retina. Am J Physiol 121:400-415.

Hassenstein B, Reichardt W (1956) Systemtheoretische analyse der zeit, reihenfolgen und vorzeichenauswertung bei der bewegungsperzeption des rüsselkafers Chlorophanus. Z Naturforsch 11:513-524.

Hausen K (1982) Motion sensitive interneurons in the optomotor system of the fly. II. The horizontal cells: receptive field organization and response characteristics. Biol Cybern 46:67-79. CrossRef

Hausen K (1984) The lobula-complex of the fly: structure, function and significance in visual behavior. In: Photoreception and vision in invertebrates (Ali M, ed), pp 523-559. New York: Plenum.

Henrie JA, Shapley R (2005) LFP power spectra in V1 cortex: the graded effect of stimulus contrast. J Neurophysiol 94:479-490. CrossRef Medline

Hubel DH, Wiesel TN (1959) Receptive fields of single neurones in the cat's striate cortex. J Physiol 148:574-591. Medline

Jansonius NM, van Hateren JH (1991) Fast temporal adaptation of on-off units in the first optic chiasm of the blowfly. J Comp Physiol A Neuroethol Sens Neural Behav Physiol 168:631-637. Medline

Joesch M, Plett J, Borst A, Reiff DF (2008) Response properties of motionsensitive visual interneurons in the lobula plate of Drosophila melanogaster. Curr Biol 18:368-374. CrossRef Medline

Joesch M, Schnell B, Raghu SV, Reiff DF, Borst A (2010) ON and OFF pathways in Drosophila motion vision. Nature 468:300-304. CrossRef Medline

Jung SN, Borst A, Haag J (2011) Flight activity alters velocity tuning of fly motion-sensitive neurons. J Neurosci 31:9231-9237. CrossRef Medline

Koch K, McLean J, Segev R, Freed MA, Berry MJ 2nd, Balasubramanian V, Sterling P (2006) How much the eye tells the brain. Curr Biol 16: 1428-1434. CrossRef Medline

Kohn A, Movshon JA (2003) Neuronal adaptation to visual motion in area MT of the macaque. Neuron 39:681-691. CrossRef Medline

Lee YJ, Nordström K (2012) Higher order motion sensitivity in fly visual circuits. Proc Natl Acad Sci U S A 109:8758-8763. CrossRef Medline
Maddess T (1986) Afterimage-like effects in the motion-sensitive neuron H1. Proc R Soc Lond B Biol Sci 228:433-459. Medline

Nordström K (2012) Neural specializations for small target detection in insects. Curr Opin Neurobiol 22:272-278. CrossRef Medline

Nordström K, O'Carroll DC (2009) Feature detection and the hypercomplex property in insects. Trends Neurosci 32:383-391. CrossRef Medline

Nordström K, Barnett PD, O'Carroll DC (2006) Insect detection of small targets moving in visual clutter. PLoS Biol 4:e54. CrossRef Medline

Nordström K, Barnett PD, Moyer de Miguel IM, Brinkworth RS, O’Carroll DC (2008) Sexual dimorphism in the hoverfly motion vision pathway. Curr Biol 18:661-667. CrossRef Medline

O'Carroll DC, Osorio D, James AC, Bush T (1992) Local feedback mediated via amacrine cells in the insect optic lobe. J Comp Physiol A Neuroethol Sens Neural Behav Physiol 171:447-455.

Osorio D (1991) Mechanisms of early visual processing in the medulla of the locust optic lobe: how self-inhibition, spatial-pooling, and signal rectification contribute to the properties of transient cells. Vis Neurosci 7:345-355. Medline

Price NS, Ibbotson MR (2002) Direction-selective neurons in the optokinetic system with long-lasting after-responses. J Neurophysiol 88: 2224-2231. CrossRef Medline

Priebe NJ, Ferster D (2012) Mechanisms of neuronal computation in mammalian visual cortex. Neuron 75:194-208. CrossRef Medline

Raghu SV, Reiff DF, Borst A (2011) Neurons with cholinergic phenotype in the visual system of Drosophila. J Comp Neurol 519:162-176. CrossRef Medline

Raghu SV, Claussen J, Borst A (2013) Neurons with GABAergic phenotype in the visual system of Drosophila. J Comp Neurol 521:252-265. CrossRef Medline

Ratliff CP, Borghuis BG, Kao YH, Sterling P, Balasubramanian V (2010) Retina is structured to process an excess of darkness in natural scenes. Proc Natl Acad Sci U S A 107:17368-17373. CrossRef Medline

Safran MN, Flanagin VL, Borst A, Sompolinsky H (2007) Adaptation and information transmission in fly motion detection. J Neurophysiol 98:3309-3320. CrossRef Medline

Solomon SG, Peirce JW, Dhruv NT, Lennie P (2004) Profound contrast adaptation early in the visual pathway. Neuron 42:155-162. CrossRef Medline

Strausfeld NJ, Bassemir UK (1985) The organisation of giant horizontalmotion-sensitive neurons and their synaptic relationships in the lateral deuterocerebrum of Calliphora erythrocephala and Musca domestica. Cell Tissue Res 242:531-550.

Straw AD, Warrant EJ, O'Carroll DC (2006) A 'bright zone' in male hoverfly (Eristalis tenax) eyes and associated faster motion detection and increased contrast sensitivity. J Exp Biol 209:4339-4354. CrossRef Medline

Suver MP, Mamiya A, Dickinson MH (2012) Octopamine neurons mediate flight-induced modulation of visual processing in Drosophila. Curr Biol 22:2294-2302. CrossRef Medline

Takemura SY, Karuppudurai T, Ting CY, Lu Z, Lee CH, Meinertzhagen IA (2011) Cholinergic circuits integrate neighboring visual signals in a Drosophila motion detection pathway. Curr Biol 21:2077-2084. CrossRef Medline

Theobald JC, Duistermars BJ, Ringach DL, Frye MA (2008) Flies see second-order motion. Curr Biol 18:R464-R465. CrossRef Medline

Thiel A, Greschner M, Ammermüller J (2006) The temporal structure of transient ON/OFF ganglion cell responses and its relation to intra-retinal processing. J Comput Neurosci 21:131-151. CrossRef Medline

Tuthill JC, Chiappe ME, Reiser MB (2011) Neural correlates of illusory motion perception in Drosophila. Proc Natl Acad Sci U S A 108:9685-9690. CrossRef Medline

Werblin FS, Dowling JE (1969) Organization of the retina of the mudpuppy, Necturus maculosus. II. Intracellular recording. J Neurophysiol 32: 339-355. Medline

Wiederman SD, Shoemaker PA, O'Carroll DC (2008) A model for the detection of moving targets in visual clutter inspired by insect physiology. PLoS ONE 3:e2784. CrossRef Medline 